\title{
Ezetimibe decreased nonalcoholic fatty liver disease activity score but not hepatic steatosis
}

\author{
Hyo Young Lee ${ }^{1}$, Dae Won Jun ${ }^{1}$, Hyun Jung Kim², Hyunwoo Oh ${ }^{1}$, Waqar Khalid Saeed ${ }^{1}$, Hyeongsik Ahn ${ }^{2}$, \\ Ramsey C. Cheung ${ }^{3}$, and Mindie H. Nguyen ${ }^{3}$
}

${ }^{1}$ Department of Internal Medicine, Hanyang University College of Medicine, Seoul; ${ }^{2}$ Department of Preventive Medicine, Korea University College of Medicine, Seoul, Korea; ${ }^{3}$ Division of Gastroenterology and Hepatology, Stanford University Medical Center, Palo Alto, CA, USA

Received: May 28, 2017

Revised : July 14, 2017

Accepted: August 1, 2017

Correspondence to

Dae Won Jun, M.D.

Department of Internal Medicine, Hanyang University College of Medicine, 222-1 Wangsim-

ni-ro, Seongdong-gu, Seoul

04763 , Korea

Tel: $+82-2-2290-8338$

Fax: +82-2-972-0068

E-mail: noshin@hanyang.ac.kr
Background/Aims: A number of clinical trials reported varying effects of cholesterol lowering agents in nonalcoholic fatty liver disease (NAFLD) patients. We, therefore, assessed the changes in hepatic steatosis and NAFLD activity score (NAS) after treatment with cholesterol lowering agents in NAFLD patients by metaanalysis.

Methods: The Cochrane Library, the MEDLINE, and the Embase databases were searched until May 2015, without any language restrictions, for randomized controlled trials (RCTs) and nonrandomized studies (NRSs). Additional references were obtained from review of bibliography of relevant articles. The quality of evidence was assessed using the grading of recommendations assessment, development and evaluation guidelines.

Results: Three RCTs $(n=98)$ and two NRSs $(n=101)$ met our study inclusion criteria (adult, NAFLD, liver biopsy). Liver biopsy was performed in all five studies, but only the three studies reported NAS. Ezetimibe significantly decreased NAS (standardized mean difference [SMD], $-0.30 ; 95 \%$ confidence interval [CI], -0.57 to -0.03 ) but not hepatic steatosis in RCT (SMD, $-0.1 ; 95 \% \mathrm{CI},-0.53$ to 0.32 ), while the effect was significant for both NAS and intrahepatic content in NRSs (SMD, -3.0; 95\% CI, -6.9 to 0.91 ).

Conclusions: Ezetimibe decreased NAS without improving hepatic steatosis.

Keywords: Meta-analysis; Non-alcoholic fatty liver disease; Hydroxymethylglutaryl-CoA reductase inhibitors; Ezetimibe

\section{INTRODUCTION}

Metabolic syndrome is a major risk factor for nonalcoholic fatty liver disease (NAFLD), with approximately half of all NAFLD patients also having hypercholesterolemia [1]. Current treatment for NAFLD consists largely of lifestyle modifications and treatment of comorbid conditions such as hyperlipidemia. Experimental studies in mice have shown that ezetimibe and statins not only reduce hepatic inflammation but also fibrosis [2]. Several studies also suggested that hydroxymethylglu- taryl-coenzyme A (HMG-CoA) reductase inhibitors may improve liver function tests and histology of NAFLD patients $[3,4]$.

Results from both randomized control trials (RCTs) and non-RCT studies (NRSs) on the effects of cholesterol lowering agents have been difficult to interpret due to the variations in study designs, diagnostic criteria and types of cholesterol lowering agents used. For instance, a sub-study of the St. Francis heart study of 455 subjects showed that, $20 \mathrm{mg}$ of atorvastatin combination with vitamins effectively reduced the odds of developing 
hepatic steatosis by $71 \%$ in healthy individuals as well as those with NAFLD [5]. Another study by Park et al. [6] which included 45 subjects showed ezetimibe as a promising agent for the treatment of NAFLD; however, this study did not have a control arm. In addition, most existing investigations were case control studies [7], and there are currently only four RCTs examining this important issue $[4,8,9]$.

A recent Cochrane systematic review in 2013 identified only two RCTs with a total 205 participants, and neither study evaluated the histological response to statin therapy [7]. The authors concluded that there were insufficient evidence to either support or refute the use of statins in patients with NAFLD.

In the present study, we investigated the efficacy of cholesterol lowering agents in biopsy-proven NAFLD patients. Primary outcome was changes in hepatic steatosis, while the secondary outcomes were improvements in NAFLD activity score (NAS) as assessed by liver biopsy.

\section{METHODS}

\section{Data source and literature source}

Two investigators independently searched MEDLINE (January 1, 1946 to May 30, 2015), Embase (January 1, 1947 to May 30, 2015) and the Cochrane Central Register of Controlled Trials (CENTRAL; January 1, 1966 to May 30, 2015) without language or publication year restriction.

The following keywords, MeSH and free text were searched through MEDLINE: NAFLD, statin, and ezetimibe (Supplementary Table 1). Bibliographies of potentially relevant articles were manually reviewed to identify additional relevant studies. The identified articles were assessed individually for inclusion (Supplementary Table 2).

\section{Study selection}

The studies were initially abstracted if they included the following keywords: NAFLD, statin, cholesterol lowering agent, ezetimibe. For inclusion, the studies were independently selected by two stages of screening using the Population Intervention Comparison Outcome framework [10]. Since the study objective was the histological effect with the lipid lowering agents, only those studies with liver biopsy results for diagnosis of NAFLD and post-treatment were included $[11,12]$. The required intervention included HMG-CoA reductase inhibitors or ezetimibe which can be administered at any dose for at least 6 months. The control group received no lipid lowering intervention or placebo, and there were no change of weight in all studies. The primary endpoint was improvement in hepatic steatosis while the secondary endpoint was improvement of NAS and safety.

\section{Data extraction}

Using a pre-defined data extraction form, two reviewers (H.Y.L. and D.W.J.) independently extracted data from each study. Any disagreement was independently reviewed by a third reviewer (H.J.K.). The following variables were extracted from the selected studies:(1) hepatic steatosis as evaluated by liver biopsy and/or quantitative fat measurement by magnetic resonance imaging (MRI); (2) NAS measurement before and after therapeutic intervention. All outcomes were assessed by differences between treated and control groups. The results were expressed as mean and standard deviations.

\section{Assessment of study methodological quality}

Two reviewers (H.Y.J. and D.W.J.) independently assessed the methodological qualities of included studies. The study quality was evaluated using the risk of bias by Cochrane for RCTs (Supplementary Fig. 1) and Newcastle Ottawa scale for NRSs (Supplementary Table 2) [13]. Any unresolved disagreements between reviewers were resolved by the third author (H.J.K.). Publication bias was not assessable due to the small numbers of studies.

\section{Statistical analysis}

We analyzed continuous data using standardized mean difference to combine trials that measure the same outcome but utilized different methods. The primary outcome was change of hepatic steatosis by liver biopsy (and MRI quantification in one study). The histological grading in NAFLD, inflammation, and fibrosis was based on scoring systems by either Brunt et al. [14] or Kleiner [15]. Secondary outcome were changes in NAS.

To assess for heterogeneity, we estimated the proportion of between-study inconsistency due to true differences between studies (rather than differences due 
to random error or chance) using the $I^{2}$ statistic, with values of $25 \%, 50 \%$, and $75 \%$ considered low, moderate, and high, respectively. Outcomes were analyzed using random effects model and standardized mean difference (SMD) to assess changes in measurements made by different scales. All analyses were performed using RevMan version 5.2 (http://community.cochrane.org/). This meta-analysis was conducted according to the Preferred Reporting Items for Systematic Revise and Meta-Analyses (PRISMA) statement.

\section{RESULTS}

\section{Identification of studies}

Fig. 1 shows the details of literature research and selection process of the meta-analysis. The initial search strategy identified 857 articles. Of these, 667 publications were excluded after reviewing the title and abstract which indicated that they did not fulfill the selection criteria (Supplementary Table 3). For the remaining 39 articles [4,6-11,13-44], we performed full manuscript review and identified five relevant studies (three RCTs and two NRSs) to include in this meta-analysis.

\section{Study characteristics and patient populations}

Table 1 describes characteristics of the five included studies. The five studies comprised a total of 199 participants who received either statins $(n=47)$ or ezetimibe $(n$ $=42)$ in the treatment group, and placebo $(n=97)$ or ur- sodeoxycholic acid (UDCA) $(\mathrm{n}=13)$ in the control group. Ezetimibe was administered for 6 months and statins was administered from 6 months to 6 years $[8,9]$. Two studies were conducted in the USA, and one each in Japan, Sweden, and Romania. The study by Nelson et al. [4], Ekstedt et al. [28] and Georgescu and Georgescu [30] used statins, while the study by Loomba et al. [8] and Takeshita et al. [9] used ezetimibe as the lipid lowering agent. By inclusion criteria, liver biopsy was performed in all five studies, but magnetic resonance spectroscopy was also used in one study [8]. The control subjects received placebo except for those in the study by Georgescu and Georgescu [30] which used UDCA. In terms of race/ethnicity, three studies $[4,28,30]$ included mostly or all Caucasian, while two studies [8,9] included mostly or all Asians. In both studies that used ezetimibe for 6 months, the baseline cholesterol level was within normal range ( 180 to $190 \mathrm{mg} / \mathrm{dL}$ ). However, in the study by Georgescu and Georgescu [30] in which statin was used, the baseline cholesterol levels were high with mean level ranging 318 to $326 \mathrm{mg} / \mathrm{dL}$. Loomba et al. [8] studied Caucasian subjects (baseline BMI, 33 to $34 \mathrm{~kg} / \mathrm{m}^{2}$ ), while Takeshita et al. [9] studied East Asian subjects with lower BMI (baseline BMI, 28 to $31 \mathrm{~kg} / \mathrm{m}^{2}$ ).

\section{Quality of the studies}

Among the three RCTs, the quality of two studies $[8,9]$ was satisfactory, but one study [4] did not have random allocation sequence, optimal allocation concealment, and detailed data description. However, treated and control

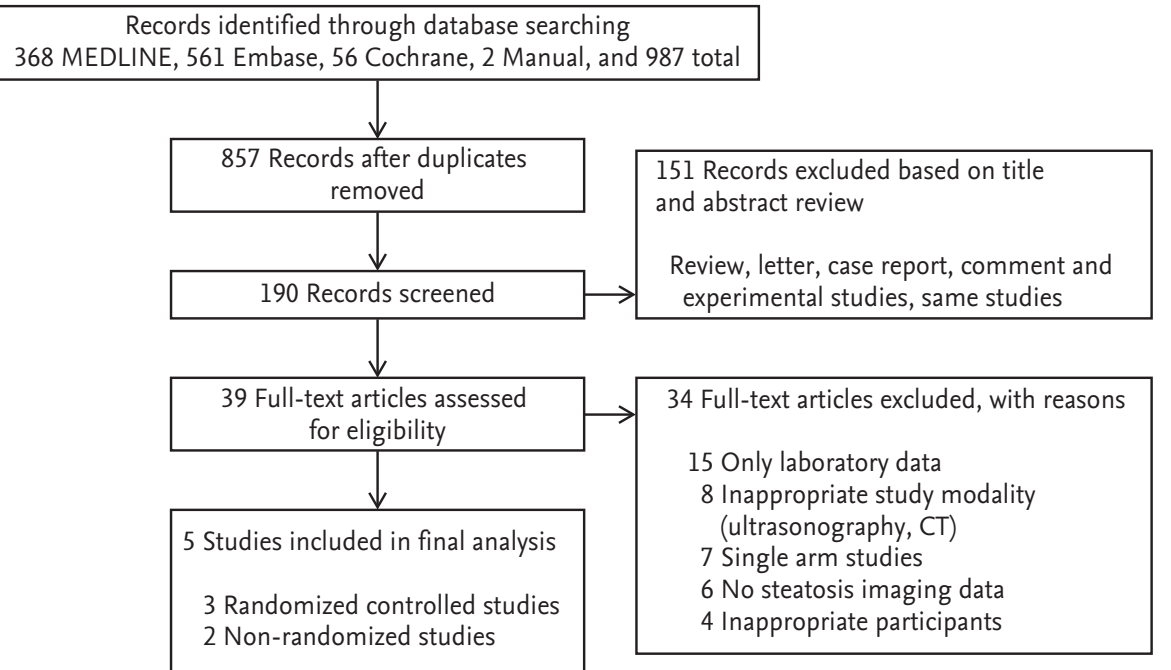

Figure 1. Preferred Reporting Items for Systematic Revise and Meta-Analyses (PRISMA) diagram of the literature search. CT, computed tomography. 
Table 1. Study characteristics

\begin{tabular}{|c|c|c|c|c|c|}
\hline Variable & $\begin{array}{l}\text { Nelson et al. } \\
(2009)[4]\end{array}$ & $\begin{array}{l}\text { Takeshita et al. } \\
\qquad(2014)[9]\end{array}$ & $\begin{array}{l}\text { Loomba et al. } \\
\qquad(2015)[8]\end{array}$ & $\begin{array}{l}\text { Georgescu et al. } \\
\quad(2007)[30]\end{array}$ & $\begin{array}{l}\text { Ekstedt et al. } \\
(2007)[28]\end{array}$ \\
\hline Study design & RCT & RCT & RCT & Open label & $\begin{array}{l}\text { Retroactive- } \\
\text { prospective }\end{array}$ \\
\hline Country & USA & Japan & USA & Romania & Sweden \\
\hline Percentage with NASH & 100 & NR & 100 & 100 & 65 \\
\hline Intervention & Simvastatin $40 \mathrm{mg}$ & Ezetimibe $10 \mathrm{mg}$ & Ezetimibe $10 \mathrm{mg}$ & Atorvastatin $10 \mathrm{mg}$ & Any statin \\
\hline Treatment duration, mon & 12 & 6 & 6 & 18.7 & 73.2 \\
\hline No. with repeat biopsy ${ }^{\mathrm{a}}$ & 10 & 16 & 17 & 10 & 17 \\
\hline $\begin{array}{l}\text { Mean duration between } \\
\text { biopsy }\end{array}$ & $\begin{array}{l}\text { Baseline (within } 6 \\
\text { mon) and } 12 \text { mon }\end{array}$ & $\begin{array}{l}\text { Baseline and } 6 \\
\text { mon }\end{array}$ & $\begin{array}{l}\text { Baseline (within } 6 \\
\text { mon) and } 6 \text { mon }\end{array}$ & $\begin{array}{l}\text { Baseline (within } 2 \\
\text { wk) and last visit }\end{array}$ & $\begin{array}{l}13.8 \pm 1.2 \text { yr from } \\
\text { first biopsy }\end{array}$ \\
\hline Race/ethnicity & $\begin{array}{l}\text { White, Hispanic, } \\
\text { African }\end{array}$ & Asian & Caucasian & Caucasian & White \\
\hline Sample size & 16 & 32 & 50 & 23 & 68 \\
\hline Male sex & 11 & 20 & 19 & NR & 48 \\
\hline Mean age, yr & 53 & 52.5 & 49.2 & 55 & 47.1 \\
\hline Cholesterol, mg/dL & $208-231$ & $170-199$ & $170-182$ & $318-326$ & $230-264$ \\
\hline BMI, $\mathrm{kg} / \mathrm{m}^{2}$, range & $34-37$ & $28-31$ & $33-34$ & 35 & $27-30$ \\
\hline Percentage of diabetes & 28 & NR & 12 & NR & 80 \\
\hline \multicolumn{6}{|c|}{ Improvement in histology, mean \pm SD } \\
\hline \multicolumn{6}{|l|}{ Steatosis (grade or \%) } \\
\hline Before & $25.0 \% \pm 14.7 \%$ & $1.56 \pm 0.18$ & $2.00 \pm 1.00$ & $2.60 \pm 0.27$ & $20.4 \% \pm 7.5 \%$ \\
\hline After & $23.8 \% \pm 21.2 \%$ & $1.31 \pm 0.15$ & $1.00 \pm 1.00$ & $1.40 \pm 0.17$ & $11.1 \% \pm 8.9 \%^{\mathrm{b}}$ \\
\hline$p$ value & 0.8847 & 0.3000 & 0.2500 & 0.0001 & 0.001 \\
\hline \multicolumn{6}{|l|}{ Lobular inflammation } \\
\hline Before & NR & NR & $1.41 \pm 0.49$ & $1.80 \pm 0.20$ & $0 \pm 0$ \\
\hline After & NR & NR & $1.65 \pm 0.59$ & $1.50 \pm 0.17$ & $0.12 \pm 0.32$ \\
\hline \multicolumn{6}{|l|}{ Ballooning } \\
\hline Before & NR & $0.69 \pm 0.20$ & $1.29 \pm 0.57$ & $1.10 \pm 0.13$ & $0.12 \pm 0.32$ \\
\hline After & NR & $0.41 \pm 0.15$ & $1.00 \pm 0.77$ & $0.80 \pm 0.10$ & $0.41 \pm 0.60$ \\
\hline \multicolumn{6}{|l|}{ Fibrosis } \\
\hline Before & $1.25 \pm 0.70$ & NR & $1.35 \pm 1.23$ & $1.50 \pm 0.17$ & $0.88 \pm 0.83$ \\
\hline After & $1.50 \pm 0.90$ & NR & $1.29 \pm 1.28$ & $1.30 \pm 0.13$ & $1.35 \pm 1.33$ \\
\hline \multicolumn{6}{|l|}{ Mean NAS } \\
\hline Before & NR & $3.71 \pm 0.50$ & $5.2 \pm 2.00$ & $6.70 \pm 1.337$ & NR \\
\hline After & NR & $3.06 \pm 0.45$ & $4.0 \pm 2.00^{c}$ & $5.00 \pm 1.563^{d}$ & NR \\
\hline$p$ value & NR & 0.1850 & 0.2910 & 0.0176 & NR \\
\hline
\end{tabular}

RCT, randomized controlled trials; NASH, nonalcoholic steatohepatitis; NR, not reported; BMI, body mass index; NSC, no statistical significant change.

${ }^{a}$ Exclude patients who complete the study but did not have repeat liver biopsy.

${ }^{\mathrm{b}} \mathrm{p}=0.01$.

${ }_{5} \%$ or $33 \%$ had a $2+$ point improvement in nonalcoholic fatty liver diseases activity score.

${ }^{\mathrm{d}}$ Mean differences -2.0 with $p<0.0001$. 


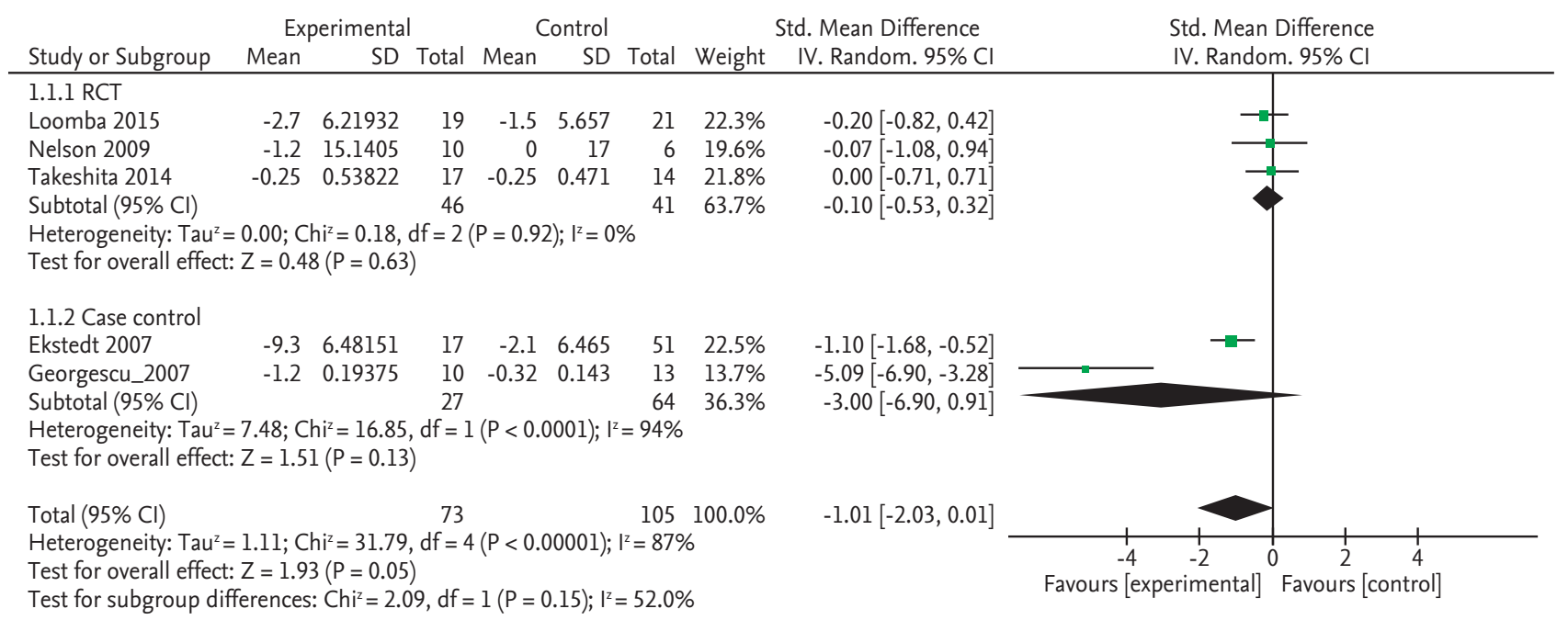

Figure 2. Forest plot for improving rate of intrahepatic fat. RCT, randomized controlled trials; SD, standard deviation; IV, interval variable; CI, confidence interval.

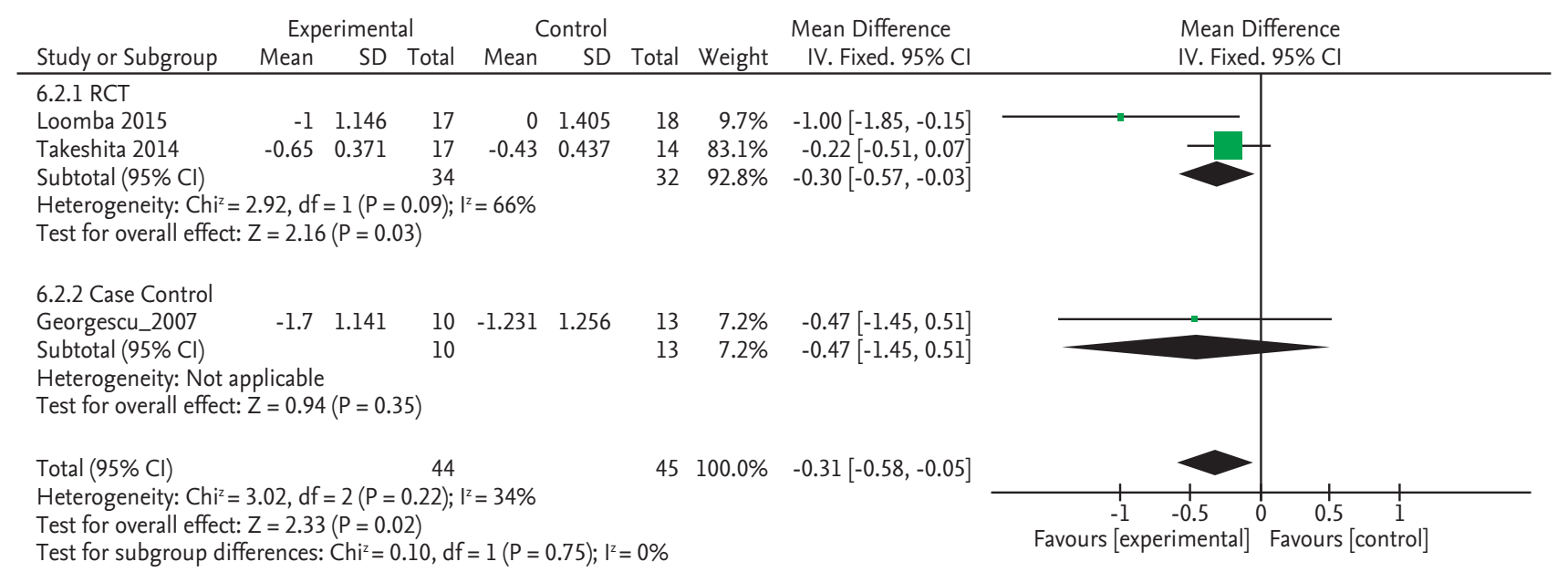

Figure 3. Forest plot for improving rate of nonalcoholic fatty liver diseases activity score in randomized controlled trials (RCT). SD, standard deviation; IV, interval variable; CI, confidence interval.

groups in all three RCTs were well-matched based on baseline characteristics with well-defined treatment response. In the two NRSs, subjects in the two groups were not well-matched since they were not randomized. The level of evidence and grade of recommendation for each outcome are summarized in Supplementary Table 2.

\section{Hepatic steatosis}

Cholesterol lowering agents did not significantly decreased the hepatic steatosis in NAFLD patients in the three RCTs (SMD, $-0.10 ; 95 \%$ confidence interval [CI], -0.53 to 0.32 ) or in two NRSs (SMD, $-3.00 ; 95 \%$ CI, -6.90 to 0.91 ) (Fig. 2).

\section{Nonalcoholic fatty liver diseases activity score}

Only two RCTs and one NRS reported the NAS data. Meta-analyzed result of the two RCT studies demonstrated a significant improvement of NAS (SMD, -0.30; 95\% CI, -0.57 to -0.03$)$. As shown in Fig. 3, pooled estimate of all three studies with available data also showed significant improvement. However, the mean reduction of NAS was modest: -1.0 in in Loomba et al. [8] and -0.65 in Takeshita et al. [9] but slightly higher in the case control study by Georgescu and Georgescu (mean, -1.7) [30]. 


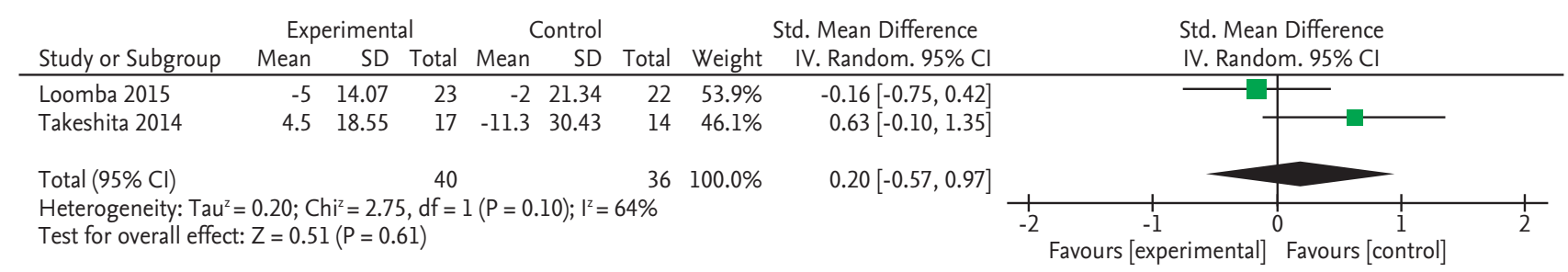

Figure 4. Forest plot for decrease of serum fasting glucose. Std., standardized; SD, standard deviation; IV, interval variable; CI, confidence interval.

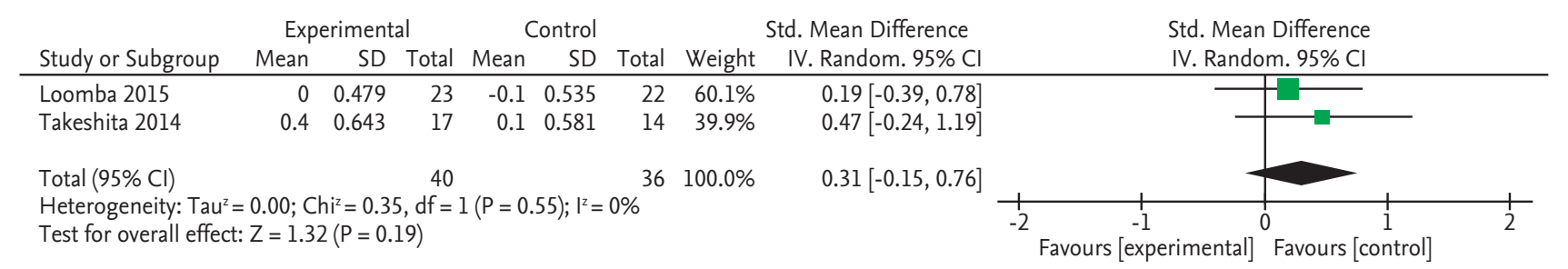

Figure 5. Forest plot for decrease of serum glycated hemoglobin. Std., standardized; SD, standard deviation; IV, interval variable; CI, confidence interval.

\section{Safety}

There was no significant change in serum fasting glucose levels in the two RCTs (SMD, 0.20; 95\% CI, -0.57 to 0.97) (Fig. 4) [8,9]. Data on glycated hemoglobin (HbAıc) changes were also only reported in these two RCTs and there was no significant change (SMD, 0.31; 95\% CI, -0.15 to 0.76 ) (Fig. 5) [8,9].

\section{DISCUSSION}

Our meta-analysis showed that ezetimibe decreased NAS (SMD, -0.30; 95\% CI, -0.57 to -0.03) without observable improvement in hepatic steatosis. A recent systematic review suggested that statin therapy may improve serum aminotransferase and ultrasound findings [7]. The fundamental differences between our meta-analysis and the previous systemic review were the quantitative methods used for assessment of hepatic steatosis. Our meta-analysis is based only on biopsy, and in one study also MRI-estimated proton density fat fraction (MRI-PDFF) to quantify hepatic fat contents. Contrary to the previous systemic review which included sonography studies for hepatic steatosis assessment, we excluded studies using the sonographic method because it is subjective and poorly quantifiable [11]. Computed tomography (CT) scan is also a less sensitive method to diagnose fatty liv- er [12], and is therefore a subjective method to estimate quantitative changes in intrahepatic fat content. Thus, we excluded sonographic and CT-based studies in our meta-analysis [32]. Recent data showed that MRI-PDFF has become the primary imaging modality to assess intrahepatic fat content due to their high correlation with liver histology [45], and its clinical use has also been approved by the Food and Drug Administration (FDA) in the USA MRI-PDFF has emerged as a reference standard to measure hepatic steatosis in the radiation zone and is used as the primary modality for endpoint measurement in several clinical trials [45].

Of the RCTs only the two studies which used ezetimibe included NAS data. These two studies showed an improvement in NAS. The study by Loomba et al. [8] used both MRI-PDFF and liver biopsy. In fact, the primary end point of the study was changes in hepatic steatosis as measured by MRI-PDFF, with paired liver biopsy performed in $77.8 \%$ of study subjects [8]. We analyzed this study as their biopsy results were well-matched with similar baseline NAS in both groups (5 points each) as well as similar proportion lost at follow-up in both groups (32\% vs. 28\%, respectively). Moreover, baseline characteristics were also similar in both groups with regards to cholesterol levels, sex and age distribution. These two studies showed a trend of improvement in alanine aminotransferase (ALT) but there was no signif- 
icant improvement when all four studies with information on ALT were included in the meta-analysis (Supplementary Fig. 2).

Several recent studies have suggested that long-term use of statins could increase the risk of diabetes mellitus and raise serum glucose levels [46]. In this meta-analysis, we did not find any significant increase in fasting serum glucose or HbAic levels following statin use for 6 months. Takeshita et al. [9] reported a significant increase in $\mathrm{HbAlc}$ following the treatment; however, there was no significant increase in HbA1c observed when improvement rate was analyzed. Moreover, statin administration was also not associated with liver toxicity (Supplementary Fig. 2).

This meta-analysis had several limitations. First, the number of included studies was small. As such, we had to pool two cholesterol lowering agents (statin and ezetimibe) together in our analysis. Even though both have lipid-lowering effects, their mechanism of action is different. Second, there is considerable heterogeneity in design and endpoints among the available studies. For example, only three of the five studies were RCTs. Third, there were considerable heterogeneity in the two NRSs. The study by Ekstedt et al. [28] found a greater improvement in hepatic steatosis but the mean baseline cholesterol level was higher in the ezetimibe intervention group than the control at, $264 \mathrm{mg} / \mathrm{dL}$ vs. $230 \mathrm{mg} / \mathrm{dL}$ ( $p=$ ०.04), respectively. In the study by Georgescu and Georgescu [30] the improvement of hepatic steatosis was also observed in the control group who were however treated with UDCA administration.

In summary, the current meta-analysis found that lipid lowering agents can improve NAS in subjects with NAFLD but effects in hepatic steatosis were not observed. Given the small number of available RCTs, as well as a small number of study subjects in interventional studies overall, further large scale RCTs are needed to effectively evaluate the effects of cholesterol-lowering agents in improving intrahepatic fat in NAFLD patients with high baseline cholesterol levels.

\section{KEY MESSAGE}

1. Ezetimibe decreased nonalcoholic fatty liver disease (NAFLD) activity score without improving hepatic steatosis.
2. Cholesterol lowering agents did not significantly decreased the hepatic steatosis in NAFLD patients.

3. There was no significant increase in glycated hemoglobin levels following statin use for 6 months.

\section{Conflict of interest}

No potential conflict of interest relevant to this article was reported.

\section{Acknowledgments}

This work was supported by a research fund from Hanyang University (HY-2014-C).

\section{REFERENCES}

1. Assy N, Kaita K, Mymin D, Levy C, Rosser B, Minuk G. Fatty infiltration of liver in hyperlipidemic patients. Dig Dis Sci 2000;45:1929-1934.

2. Van Rooyen DM, Gan LT, Yeh MM, et al. Pharmacological cholesterol lowering reverses fibrotic NASH in obese, diabetic mice with metabolic syndrome. J Hepatol 2013;59:144-152.

3. Athyros VG, Katsiki N, Karagiannis A, Mikhailidis DP. Statins and nonalcoholic fatty liver disease: a bright future? Expert Opin Investig Drugs 2013;22:1089-1093.

4. Nelson A, Torres DM, Morgan AE, Fincke C, Harrison SA. A pilot study using simvastatin in the treatment of nonalcoholic steatohepatitis: a randomized placebo-controlled trial. J Clin Gastroenterol 2009;43:990-994.

5. Foster T, Budoff MJ, Saab S, Ahmadi N, Gordon C, Guerci AD. Atorvastatin and antioxidants for the treatment of nonalcoholic fatty liver disease: the St Francis Heart Study randomized clinical trial. Am J Gastroenterol 2011; 106:71-77.

6. Park H, Shima T, Yamaguchi K, et al. Efficacy of longterm ezetimibe therapy in patients with nonalcoholic fatty liver disease. J Gastroenterol 2011;46:101-107.

7. Eslami L, Merat S, Malekzadeh R, Nasseri-Moghaddam $\mathrm{S}$, Aramin H. Statins for non-alcoholic fatty liver disease and non-alcoholic steatohepatitis. Cochrane Database Syst Rev 2013;(12):CDoo8623. 
8. Loomba R, Sirlin CB, Ang B, et al. Ezetimibe for the treatment of nonalcoholic steatohepatitis: assessment by novel magnetic resonance imaging and magnetic resonance elastography in a randomized trial (MOZART trial). Hepatology 2015;61:1239-1250.

9. Takeshita Y, Takamura T, Honda M, et al. The effects of ezetimibe on non-alcoholic fatty liver disease and glucose metabolism: a randomised controlled trial. Diabetologia 2014;57:878-890.

10. Huang X, Lin J, Demner-Fushman D. Evaluation of PICO as a knowledge representation for clinical questions. AMIA Annu Symp Proc 2006;2006:359-363.

11. Lee SS, Park SH. Radiologic evaluation of nonalcoholic fatty liver disease. World J Gastroenterol 2014;20:73927402.

12. Ma X, Holalkere NS, Kambadakone RA, Mino-Kenudson M, Hahn PF, Sahani DV. Imaging-based quantification of hepatic fat: methods and clinical applications. Radiographics 2009;29:1253-1277.

13. Lo CK, Mertz D, Loeb M. Newcastle-Ottawa scale: comparing reviewers' to authors' assessments. BMC Med Res Methodol 2014;14:45.

14. Brunt EM, Janney CG, Di Bisceglie AM, NeuschwanderTetri BA, Bacon BR. Nonalcoholic steatohepatitis: a proposal for grading and staging the histological lesions. Am J Gastroenterol 1999;94:2467-2474.

15. Kleiner DE, Brunt EM, Van Natta M, et al. Design and validation of a histological scoring system for nonalcoholic fatty liver disease. Hepatology 2005;41:1313-1321.

16. Abel T, Feher J, Dinya E, Eldin MG, Kovacs A. Safety and efficacy of combined ezetimibe/simvastatin treatment and simvastatin monotherapy in patients with nonalcoholic fatty liver disease. Med Sci Monit 2009;15:MS6MS11.

17. Abel T, Feher J, Dinya E, Gamal Eldin M, Kovacs A. Efficacy and safety of ezetimibe/simvastatin combination therapy in patients with type 2 diabetes and nonalcoholic fatty liver disease. Orv Hetil 2009;150:989-993.

18. Aggarwal V, Palmer CS, Yan KK, Lloyd AR, Zekry A. Statins and liver injury in morbidly obese subjects with nonalcoholic fatty liver disease. Hepatology 2009;50:789A.

19. Ahmed $\mathrm{MH}$. Ezetimibe and recent clinical trials: a look on the bright side. Expert Opin Drug Saf 2010;9:511-514.

20. Arendt BM, Allard JP. Effect of atorvastatin, vitamin E and $\mathrm{C}$ on nonalcoholic fatty liver disease: is the combination required? Am J Gastroenterol 2011;106:78-80.
21. Blais P, Lin M, Kramer JR, El-Serag HB, Kanwal F. Statins are underutilized in patients with nonalcoholic fatty liver disease and dyslipidemia. Dig Dis Sci 2016;61:1714-1720.

22. Bril F, Lomonaco R, Orsak B, et al. Safety of statin therapy in patients with prediabetes or T2DM and NASH: a longterm prospective study. Diabetes 2013;62(Suppl 1):A164.

23. Carnelutti A, Donnini D, Nadalutti G, et al. Effect of statin therapy vs diet in hypercholesterolemic patients affected by nonalcoholic steatohepatitis (NASH). Dig Liver Dis 2012;44(Suppl 1):S25-S26.

24. Chan DC, Watts GF, Gan SK, Ooi EM, Barrett PH. Effect of ezetimibe on hepatic fat, inflammatory markers, and apolipoprotein B-10o kinetics in insulin-resistant obese subjects on a weight loss diet. Diabetes Care 2010;33:11341139.

25. De Keyser CE, Koehler EM, Schouten JN, Hofman A, Janssen HL, Stricker BH. Association between statin therapy and non-alcoholic fatty liver disease in a large population-based study. Pharmacoepidemiol Drug Saf 2013;22:373.

26. Drapkina OM, Ivashkin VT. Treatment of non-alcoholic fatty liver disease and dyslipidemia in patients with metabolic syndrome using simvastatin and ursodeoxycholic acid. Diab Vasc Dis Res 2011;8:56-57.

27. Drapkina OM, Korneeva ON, Ivashkin VT. Ademetionine and simvastatin in patients with nonalcoholic fatty liver disease and metabolic syndrome. Endocr Pract 2011;17:21A-22A.

28. Ekstedt M, Franzen LE, Mathiesen UL, Holmqvist M, Bodemar G, Kechagias S. Statins in non-alcoholic fatty liver disease and chronically elevated liver enzymes: a histopathological follow-up study. J Hepatol 2007;47:135141.

29. Elsheikh E, Younoszai Z, Otgonsuren M, et al. Angiogenic growth factors associated with statins use in patients with nonalcoholic fatty liver disease (NAFLD) and coronary artery disease (CAD). Gastroenterology 2014;146(5 Suppl 1):S710.

30. Georgescu EF, Georgescu M. Therapeutic options in non-alcoholic steatohepatitis (NASH): are all agents alike? Results of a preliminary study. J Gastrointestin Liver Dis 2007;16:39-46.

31. Kargiotis K, Katsiki N, Athyros VG, et al. Effect of rosuvastatin on non-alcoholic steatohepatitis in patients with metabolic syndrome and hypercholesterolaemia: a preliminary report. Curr Vasc Pharmacol 2014;12:505-511. 
32. Kiyici M, Gulten M, Gurel S, et al. Ursodeoxycholic acid and atorvastatin in the treatment of nonalcoholic steatohepatitis. Can J Gastroenterol 2003;17:713-718.

33. Koehler EM, De Keyser CE, Schouten JN, Hansen BE, Janssen HL, Stricker BH. Association between statin use and nonalcoholic fatty liver disease in a population-based study. Hepatology 2012;56 Suppl 1:595A-596A.

34. Maroni L, Castiglioni L, Marino F, et al. Achievement of lipid targets in non alcoholic fatty liver disease during statin treatment. J Hypertens 2010;28(Suppl A):e547.

35. Maroni L, Guasti L, Castiglioni L, et al. Lipid targets during statin treatment in dyslipidemic patients affected by nonalcoholic fatty liver disease. Am J Med Sci 2011;342:383-387.

36. Mihaila RG, Nedelcu L, Fratila O, Rezi EC, Domnariu C, Deac M. Effects of lovastatin and pentoxyphyllin in nonalcoholic steatohepatitis. Hepatogastroenterology 2009; 56:1117-1121.

37. Oni E, Sinha P, Karim A, et al. Statin use is not associated with presence of and severity of non-alcoholic fatty liver disease. J Am Coll Cardiol 2013;61(10 Suppl S):E1427.

38. Patel A, Gawrieh S, Rizvi S, Xiang Q, Szabo A, Saeian K. Management strategies used for nonalcoholic fatty liver disease: survey of AASLD members. Gastroenterology 2009;136:A847.

39. Pireau L, Bailly S, Descamps OS. Does ezetimibe could correct hepatic steatosis? Acta Clin Belg 2013;68:463.
40. Reihner E, Rudling M, Stahlberg D, et al. Effect of pravastatin on hepatic cholesterol metabolism. Fortschr Med 1991;109:189-194.

41. Riley P, Sudarshi D, Johal M, et al. Weight loss, dietary advice and statin therapy in non-alcoholic fatty liver disease: a retrospective study. Int J Clin Pract 2008;62:374-381.

42. Samy W, Hassanian MA. Paraoxonase-1 activity, malondialdehyde and glutathione peroxidase in non-alcoholic fatty liver disease and the effect of atorvastatin. Arab J Gastroenterol 2011;12:80-85.

43. Skrypnyk IM, Dubrovins'ka TV. Optimization of longterm treatment with rosuvastatin of patients with myocardial infarction in combination with non-alcoholic steatohepatitis. Lik Sprava 2014;(5-6):113-121.

44. Zvenigorodskaja L, Cherkashova E, Samsonova N, Melnikova N. Evaluation of effectiveness in the hypolipidemic therapy of patients with atherogenic dislipoproteinemia and nonalcoholic fatty liver disease. Am J Hypertens 2009;22(Suppl 1):10.

45. Permutt Z, Le TA, Peterson MR, et al. Correlation between liver histology and novel magnetic resonance imaging in adult patients with non-alcoholic fatty liver disease: MRI accurately quantifies hepatic steatosis in NAFLD. Aliment Pharmacol Ther 2012;36:22-29.

46. Sattar N, Preiss D, Murray HM, et al. Statins and risk of incident diabetes: a collaborative meta-analysis of randomised statin trials. Lancet 2010;375:735-742. 
Supplementary Table 1. Search strategy

\begin{tabular}{|c|c|c|}
\hline Database & Time span & Search strategy \\
\hline Medline & $\begin{array}{l}1946- \\
2015.05\end{array}$ & $\begin{array}{l}\text { 1. ezetimibe[tiab] OR ezetimib[tiab] } 1835 \\
\text { 2. "ezetimibe" [Supplementary Concept] } 1320 \\
\text { 3. } 1 \text { OR } 2085 \\
\text { 4. ("Hydroxymethylglutaryl-CoA Reductase Inhibitors"[Mesh]) OR "Hydroxymethylglutaryl-CoA } \\
\text { Reductase Inhibitors" [Pharmacological Action] } 30544 \\
\text { 5. Statins[tiab] OR Statin[tiab] OR "Hydroxymethylglutaryl-CoA Reductase Inhibitors"[tiab] } \\
\text { OR "HMG-CoA Reductase Inhibitors"[tiab] OR "HMG-CoA Reductase Inhibitor"[tiab] OR } \\
\text { "HMG-CoA Inhibitors"[tiab] OR "HMG-CoA Inhibitor"[tiab] OR atorvastatin[tiab] OR BMY } \\
\text { 21950[tiab] OR cerivastatin[tiab] OR crilvastatin[tiab] OR fermodulin[tiab] OR fluvastatin[tiab] OR } \\
\text { Lovastatin[tiab] OR Meglutol[tiab] OR mevastatin[tiab] OR "phosphoadenosinediphosphoribose } \\
\text { "[tiab] OR pitavastatin[tiab] OR Pravastatin[tiab] OR red yeast rice[tiab] OR rosuvastatin[tiab] OR } \\
\text { Simvastatin[tiab] 37958 } \\
\text { 6. } 4 \text { OR } 543462 \\
\text { 7. } 3 \text { OR } 644027 \\
\text { 8. steatohepatitis[tiab] OR Steatohepatitides[tiab] OR "fatty liver"[tiab] OR "hepatic fat"[tiab] 1750o } \\
\text { 9. (("Fatty Liver"[Mesh:NoExp]) OR "Non-alcoholic Fatty Liver Disease"[Mesh]) OR("Liver/ } \\
\text { metabolism"[Mesh] OR "Liver/pathology"[Mesh]) 280o89 } \\
\text { 10. } 8 \text { OR } 9285684 \\
\text { 11. } 7 \text { AND } 101464 \\
\text { 12. (groups[tiab] OR trial[tiab] OR randomly[tiab] OR "drug therapy"[subheading] OR placebo[tiab] } \\
\text { OR randomized[tiab] OR "controlled clinical trial"[ptyp] OR "randomized controlled trial"[ptyp]) } \\
\text { NOT (animals[Mesh Term] NOT (humans[Mesh Term] AND animals[Mesh Term])) 3081519 } \\
\text { 13. } 11 \text { AND } 12368\end{array}$ \\
\hline Embase & $\begin{array}{l}1974- \\
2015.05\end{array}$ & $\begin{array}{l}\text { 1. ezetimibe:ab,ti OR ezetimib:ab,ti } 2933 \\
\text { 2. 'ezetimibe'/exp } 6237 \\
\text { 3. } 1 \text { OR } 26652 \\
\text { 4. 'hydroxymethylglutaryl coenzyme A reductase inhibitor'/exp } 101806 \\
\text { 5. Statins:ab,ti OR Statin:ab,ti OR 'Hydroxymethylglutaryl-CoA Reductase Inhibitors':ab,ti OR } \\
\text { 'HMG-CoA Reductase Inhibitors':ab,ti OR 'HMG-CoA Reductase Inhibitor':ab,ti OR 'HMG-CoA } \\
\text { Inhibitors':ab,ti OR 'HMG-CoA Inhibitor':ab,ti OR atorvastatin:ab,ti OR cerivastatin:ab,ti OR } \\
\text { crilvastatin:ab,ti OR fermodulin:ab,ti OR fluvastatin:ab,ti OR Lovastatin:ab,ti OR Meglutol:ab,ti } \\
\text { OR mevastatin:ab,ti OR 'phosphoadenosinediphosphoribose':ab,ti OR pitavastatin:ab,ti OR } \\
\text { Pravastatin:ab,ti OR redyeastrice:ab,ti OR rosuvastatin:ab,ti OR Simvastatin:ab,ti } 56766 \\
\text { 6. } 4 \text { OR } 5108937 \\
\text { 7. } 3 \text { OR } 6 \text { 109970 } \\
\text { 8. steatohepatitis:ab,ti OR Steatohepatitides:ab,ti OR 'fatty liver':ab,ti OR 'hepatic fat':ab,ti 26638 } \\
\text { 9. 'fatty liver'/de OR 'nonalcoholic fatty liver'/exp 39529 } \\
\text { 10. } 8 \text { OR } 943645 \\
\text { 11. } 7 \text { AND } 101417 \\
\text { 12. 'crossover procedure'/exp OR 'double blind procedure'/exp OR 'randomized controlled trial'/ } \\
\text { exp OR 'single blind procedure'/exp OR random* OR factorial* OR crossover* OR 'cross over' OR } \\
\text { 'cross-over' OR placebo* OR (doubl* AND blind*) OR (sing1* AND blind*) OR assign* OR allocat* } \\
\text { OR volunteer* } 1766501 \\
\text { 13. } 11 \text { AND } 12417 \\
\text { 14. } 11 \text { AND ('conference abstract'/it OR 'conference review'/it) 180 } \\
\text { 15. } 13 \text { OR } 14561\end{array}$ \\
\hline
\end{tabular}

(Continued) 


\section{Supplementary Table 1. Continued}

\begin{tabular}{|c|c|c|}
\hline Database & Time span & Search strategy \\
\hline Cochrane & 2015.05 & $\begin{array}{l}\text { 1. ezetimibe or ezetimib:ti,ab,kw } 622 \\
\text { 2. MeSH descriptor: [Hydroxymethylglutaryl-CoA Reductase Inhibitors] explode all trees } 2843 \\
\text { 3. MeSH descriptor: [Hydroxymethylglutaryl-CoA Reductase Inhibitors] explode all trees and with } \\
\text { qualifier(s): [Pharmacology - PD] } 363 \\
\text { 4. Statins or Statin or "Hydroxymethylglutaryl-CoA Reductase Inhibitors" or "HMG-CoA Reductase } \\
\text { Inhibitors" or "HMG-CoA Reductase Inhibitor" or "HMG-CoA Inhibitors" or "HMG-CoA Inhibi- } \\
\text { tor" or atorvastatin or BMY } 21950 \text { or cerivastatin or crilvastatin or fermodulin or fluvastatin or } \\
\text { Lovastatin or Meglutol or mevastatin or "phosphoadenosinediphosphoribose" or pitavastatin or } \\
\text { Pravastatin or red yeast rice or rosuvastatin or Simvastatin:ti,ab,kw } 9064 \\
\text { 5. } 1 \text { - } 4 \text { / OR } 9151 \\
\text { 6. steatohepatitis or Steatohepatitides or "fatty liver" or "hepatic fat":ti,ab,kw } 869 \\
\text { 7. MeSH descriptor: [Fatty Liver] this term only } 306 \\
\text { 8. MeSH descriptor: [Non-alcoholic Fatty Liver Disease] explode all trees } 17 \\
\text { 9. MeSH descriptor: [Liver] explode all trees and with qualifier(s): [Metabolism - ME] } 765 \\
\text { 10. MeSH descriptor: [Liver] explode all trees and with qualifier(s): [Pathology - PA] } 684 \\
\text { 11. } 6 \text { - } 10 \text { / OR } 2147 \\
\text { 12. } 5 \text { AND } 1158 \\
\text { 13. } 12 \text { / Trial } 56\end{array}$ \\
\hline KoreaMed & 2015 & $\begin{array}{l}\text { 1. ezetimibe[ALL] OR ezetimib[ALL] } \\
\text { 2. Statins[ALL] OR Statin[ALL] OR "Hydroxymethylglutaryl-CoA Reductase Inhibitors"[ALL] OR } \\
\text { "HMG-CoA Reductase Inhibitors"[ALL] OR "HMG-CoA Reductase Inhibitor"[ALL] OR "HMG- } \\
\text { CoA Inhibitors"[ALL] OR "HMG-CoA Inhibitor"[ALL] OR atorvastatin[ALL] OR BMY 2195O[ALL] } \\
\text { OR cerivastatin[ALL] OR crilvastatin[ALL] OR fermodulin[ALL] OR fluvastatin[ALL] OR } \\
\text { Lovastatin[ALL] OR Meglutol[ALL] OR mevastatin[ALL] OR "phosphoadenosinediphosphoribose" } \\
\text { [ALL] OR pitavastatin[ALL] OR Pravastatin[ALL] OR red yeast rice[ALL] OR rosuvastatin[ALL] OR } \\
\text { Simvastatin[ALL] } \\
\text { 3. } 1 \text { OR } 2 \text { 103 } \\
\text { 4. steatohepatitis[ALL] OR Steatohepatitides[ALL] OR "fatty liver"[ALL] OR "hepatic fat"[ALL] } \\
\text { 5.3 AND } 42\end{array}$ \\
\hline
\end{tabular}


Lee HY, et al. Ezetimibe decreased NAS

Supplementary Table 2. Ottawa quality assessment scale Cohort studies

\begin{tabular}{|c|c|c|c|}
\hline Bias & & $\begin{array}{c}\text { Ekstedt et al. } \\
(2007)[28]\end{array}$ & $\begin{array}{l}\text { Georgescu et } \\
\text { al. (2007) [30] }\end{array}$ \\
\hline \multirow[t]{4}{*}{ Selection } & (1) Representativeness of the exposed cohort & $\star$ & $\star$ \\
\hline & (2) Selection of the non-exposed cohort & $\star$ & $\star$ \\
\hline & (3) Ascertainment of exposure & $\star$ & $\star$ \\
\hline & (4) Demonstration that outcome of interest was not present at start of study & & $\star$ \\
\hline \multirow{4}{*}{$\begin{array}{l}\text { Comparability } \\
\text { outcome }\end{array}$} & Comparability of cohorts on the basis of the design or analysis & & \\
\hline & (1) Assessment of outcome & $\star$ & $\star$ \\
\hline & (2) Was follow-up long enough for outcomes to occur & $\star$ & $\star$ \\
\hline & (3) Adequacy of follow up of cohort & $\star$ & $\star$ \\
\hline
\end{tabular}


Supplementary Table 3. Characteristics of excluded studies (ordered by study ID)

\begin{tabular}{|c|c|c|}
\hline Study & Journal & Reason for exclusion \\
\hline Abdelmalek (2010) & Am J Gastroenterol 105:S116 & Only an abstract of the study was available \\
\hline Abel (2009) & Med Sci Monit 15(12):Ms6-11 & Inappropriate primary end point (only laboratory data) \\
\hline Abel (2009) & Orv Hetil 150(21):989-993 & Inappropriate primary end point (only laboratory data) \\
\hline Adams (2004) & Indian J Gastroenterol 23(4):127-128 & Review \\
\hline Adams (2006) & Postgrad Med J 82(967):315-322 & Inappropriate intervention \\
\hline Adams (2015) & Nat Rev Gastroenterol Hepatol 12(3):126-127 & Review \\
\hline Aggarwal (2009) & Hepatology 50:789A & Inappropriate primary end point (no steatosis data) \\
\hline Ahmed (2006) & Med Hypotheses 66(2):440-441 & Review \\
\hline Ahmed (2006) & Scand J Gastroenterol 41(5):631 & Review \\
\hline Ahmed (2009) & Diabetes ObesMetab 11(3):188-195 & Review \\
\hline Ahmed (2010) & Expert Opin Drug Saf 9(4):511-514 & Inappropriate participants \\
\hline Ahmed (2010) & Drug Discov Today 15(15-16):590-595 & Review \\
\hline Antonopoulos (2006) & Atherosclerosis 184(1):233-234 & Review \\
\hline Arendt (2011) & Am J Gastroenterol 106:78-80 & Inappropriate primary end point (no steatosis data) \\
\hline Athyros (2006) & Curr Med Res Opin 22:873-883 & Inappropriate study modality (ultrasonography) \\
\hline Athyros (2011) & Ann Med 43(3):167-171 & Review \\
\hline Athyros (2013) & Expert Opin Investig Drugs 22(9):1089-1093 & Review \\
\hline Averna $(2015)$ & Atheroscler Suppl 17(C):27-34 & Review \\
\hline Bayard (2006) & Am Fam Physician 73(11):1961-1969 & Review \\
\hline Bays (2014) & J Clin Lipidol 8(3 Suppl):S47-57 & Review \\
\hline Beaton (2012) & Can J Gastroenterol 26(6):353-357 & Review \\
\hline Blais (2015) & Gastroenterology 148(4):S982. & Inappropriate study design (single arm study) \\
\hline $\operatorname{Bril}(2013)$ & Diabetes 62, A164 DOI:10.2337/db13-388-679 & Inappropriate primary end point (no steatosis data) \\
\hline Budoff(2009) & J Am Coll Cardiol 53(10):A276 & only an abstract of the study was available \\
\hline Bugianesi (2004) & Clin Gastroenterol 18(6 SPEC.ISS.):1105-1116 & Review \\
\hline Buscher (2004) & Dtsch Med Wochenschr 129(SUPPL. 2):S60-S62 & Review \\
\hline Calamita (2007) & Expert Opin Ther Targets 11(9):1231-1249 & Review \\
\hline $\mathrm{Cao}(2 \mathrm{O} 2)$ & Zhonghua Gan Zang Bing Za Zhi 20(4):304-309 & Inappropriate study design (rat model) \\
\hline Carnelutti (2012) & Dig Liver Dis 44:S25-S26 & Inappropriate primary end point (no steatosis data) \\
\hline Chalasani (2005) & Hepatology 41(4):690-695 & Review \\
\hline Chan (2007) & J Gastroenterol Hepatol (Australia) 22(6):801-808 & Review \\
\hline Chan (2009) & Atheroscler Suppl 1o(2) & Same study (Chan 2010) \\
\hline Chan (2010) & Diabetes Care 33:1134-1139 DOI:10.2337/dco9-1765 & Inappropriate participants (patients with central obesity) \\
\hline Chang (2013) & FASEB J 27 & Inappropriate study design (rat model) \\
\hline Chuthan (2013) & Minerva Gastroenterol Dietol 59(1):69-87 & Review \\
\hline Congdon (2006) & J Fam Pract 55(10):905-906 & Review \\
\hline Conjeevaram (2009) & Hepatology (Baltimore, MD) 50:774a & Inappropriate intervention (fenofibrate) \\
\hline de Alwis (2008) & J Hepatol 48(SUPPL. 1):S104-S112 & Review \\
\hline de Alwis (2010) & Curr Pharm Des 16(17):1958-1962 & Review \\
\hline De Keyser (2013) & Pharmacoepidemiol Drug Saf 22:373 & Inappropriate study design (single arm study) \\
\hline Del Ben (2014) & World J Gastroenterol (26):8341-8350 & Review \\
\hline Delgado (2008) & Eur J Intern Med 19(2):75-82 & Review \\
\hline
\end{tabular}




\section{Supplementary Table 3. Continued}

\begin{tabular}{|c|c|c|}
\hline Study & Journal & Reason for exclusion \\
\hline Della Corte (2011) & Expert Opin Pharmacother 12(12):1901-1911 & Review \\
\hline $\operatorname{Dima}(2012)$ & Rom J Intern Med 50(1):19-25 & Review \\
\hline Drapkina (2011) & Endocr Pract 17(6):21A-22A & Inappropriate primary end point (only laboratory data) \\
\hline Drapkina (2011) & Diab Vasc Dis Res 8(1):56-57 & Inappropriate primary end point (only laboratory data) \\
\hline Drapkina (2012) & J Hepatol 56:S507 & Inappropriate primary end point (only laboratory data) \\
\hline Duvnjak (2007) & World J Gastroenterol 13(34):4539-4550 & Review \\
\hline Duvnjak (2009) & J Physiol Pharmacol 6o Suppl 7:57-66 & Review \\
\hline Elsheikh (2014) & Gastroenterology 146(5):S-710 & Inappropriate primary end point (only laboratory data) \\
\hline Enjoji (2010) & Lipids Health Dis 9:29 & Inappropriate study modality (ultrasonography) \\
\hline Eslami (2013) & Cochrane Database Syst Rev 12:Cdoo8623 & Review \\
\hline Farrell (2014) & Clin Gastroenterol Hepatol 12(1):152-155 & Review \\
\hline Federico (2006) & Dig Liver Dis 38(11):789-801 & Review \\
\hline Filippatos (2010) & World J Hepatol 2(4):139-142 & Review \\
\hline Foster (2010) & Gastroenterology 138(5):S803 & Same study (Foster 2011) \\
\hline Foster (2011) & Am J Gastroenterol 106:71-77 & Only an abstract of the study was available \\
\hline Gitto (2015) & Gastroenterol Res Pract 2015 & Review \\
\hline Gomez(2006) & Aliment Pharmacol Ther 23(11):1643-1647 & Inappropriate study modality (ultrasonography) \\
\hline Gossard (2011) & Drugs Today (Barc) 47(12):915-922 & Review \\
\hline Hardwick (2011) & Drug Metab Rev 43:78 & Inappropriate study design (rat model) \\
\hline Harrison $(2003)$ & Drugs 63(22):2379-2394 & Review \\
\hline Harrison (2004) & Clin Liver Dis 8(3):715-728 & Review \\
\hline Harrison (2014) & Hepatology 60:630A & Review \\
\hline Hatzitolios (2004) & Indian J Gastroenterol 23(4):131-134 & Inappropriate study modality (ultrasonography) \\
\hline Hughes (2006) & Med Hypotheses 67(6):1463-1464 & Review \\
\hline Hyogo (2008) & Metabolism 57:1711-1718 & Same study (hyogo 2012) \\
\hline Hyogo (2012) & Dig Liver Dis $44(6): 492-496$ & Inappropriate study design (single arm study) \\
\hline Ioannou (2015) & J Lipid Res 56(2):277-285 & Inappropriate study design (rat model) \\
\hline Ivanova (2013) & Eur J PrevCardiol 20(1):S76 & Inappropriate study modality (ultrasonography) \\
\hline Kalaitzakis (2014) & Minerva Gastroenterol Dietol 6o(1):15-24 & Review \\
\hline Karagiannis (2014) & Curr Vasc Pharmacol 12:505-511 & Inappropriate primary end point (no steatosis data) \\
\hline Kashi (2008) & Semin Liver Dis 28(4):396-406 & Review \\
\hline Khedmat (2011) & Hepat Mon $11(2): 74-85$ & Review \\
\hline $\operatorname{Kim}(2012)$ & Gastroenterology 142(5): $\mathrm{S}_{545}$ & Inappropriate study design (rat model) \\
\hline Kimura (2010) & J Gastroenterol 45(7):750-757 & Inappropriate study design (single arm study) \\
\hline Koehler (2012) & Hepatology $56: 595 \mathrm{~A}-596 \mathrm{~A}$ & Inappropriate primary end point (only laboratory data) \\
\hline Kopec (2011) & Nutr Clin Pract 26(5):565-576 & Review \\
\hline Korneeva (2010) & J Hepatol 52:S146 & Same study (Korneeva 2012) \\
\hline Korneeva (2012) & Cardiovasc Res 93:S79-S80 & Inappropriate study modality (ultrasonography) \\
\hline Krawczyk (2010) & Best Pract Res Clin Gastroenterol 24(5):695-708 & Review \\
\hline $\operatorname{Lam}(2009)$ & Ann Hepatol 8(SUPPL. 1):S51-S59 & Review \\
\hline $\operatorname{Lam}(2010)$ & Therap Adv Gastroenterol 3(2):121-137 & Review \\
\hline $\operatorname{Le}(2012)$ & J Clin Exp Hepatol 2(2):156-173 & Review \\
\hline
\end{tabular}




\section{Supplementary Table 3. Continued}

\begin{tabular}{|c|c|c|}
\hline Study & Journal & Reason for exclusion \\
\hline Leerapun (2011) & Hepatol Int 5(1):8-9 & Review \\
\hline Lewis (2010) & Dig Dis Sci 55(3):560-578 & Review \\
\hline Liangpunsakul (2003) & Curr Treat Options Gastroenterol 6(6):455-463 & Review \\
\hline Liberopoulos (2006) & Aliment Pharmacol Ther 24(4):698-699 & Review \\
\hline Lomonaco (2013) & Drugs 73(1):1-14 & Review \\
\hline Loomba (2014) & $\begin{array}{l}\text { Hepatology (Baltimore, MD) 6o:226a } \\
\text { DOI:10.1002/hep.27457 }\end{array}$ & Same study (Loomba 2015) \\
\hline Lowyck (2007) & Acta Gastroenterol Belg 70(4):381-388 & Review \\
\hline Machado (2014) & Expert Rev Gastroenterol Hepatol 8(5):487-500 & Review \\
\hline Malinowski (2013) & Pharmacotherapy 33(2):223-242 & Review \\
\hline Marchesini (2011) & Expert Opin Emerg Drugs 16:121-136 & Review \\
\hline Maroni (2010) & J Hypertens 28:e547 & Inappropriate primary end point (only laboratory data) \\
\hline Maroni (2011) & Am J Med Sci 342(5):383-387 & Inappropriate primary end point (only laboratory data) \\
\hline Marzocchi (2003) & Gastroenterol Int 16(1-2):9-16 & Review \\
\hline Mathur (2012) & J Am Coll Surg 215(3):S25 & Inappropriate study design (rat model) \\
\hline Mazzella (2014) & Clin Liver Dis 18(1):73-89 & Review \\
\hline Mazzella (2015) & Gastroenterology 149(2):274-278 & Review \\
\hline McAvoy (2006) & Br J Diab Vasc Dis 6(6):251-26o & Review \\
\hline Mehta (2010) & Ther Adv Endocrinol Metab 1(3):101-115 & Review \\
\hline Mendez (2007) & Liver Int 27(9):1157-1165 & Review \\
\hline Miao (2014) & Am J Gastroenterol 109:S186 & Only an abstract of the study was available \\
\hline Mihaila (2009) & Hepatogastroenterology 56(93):1117-1121 & Inappropriate primary end point (only laboratory data) \\
\hline Mihaila (2012) & Arch Balkan Med Union 47(3):249-254 & Review \\
\hline Mishra (2007) & Curr Drug Discov Technol 4(2):133-140 & Review \\
\hline Moreno (2005) & Med Clin (Barc) 125(3):108-116 & Review \\
\hline Moscatiello (2008) & Mini Rev Med Chem 8(8):767-775 & Review \\
\hline Moseley (2008) & J Clin Gastroenterol 42(4):332-335 & Review \\
\hline Mouzaki (2012) & Ann Gastroenterol 25(3):207-217 & Review \\
\hline Musso (2010) & Hepatology 52(1):79-104 & Review \\
\hline Musso (2010) & Obes Rev $11(6): 430-445$ & Review \\
\hline Musso (20103 & Curr Pharm Des 19(29):5297-5313 & Review \\
\hline Musso (2011) & Curr Opin Lipidol 22(6):489-496 & Review \\
\hline Musso (2014) & Diabetologia 57(5):850-855 & Review \\
\hline Nguyen (2012) & $\begin{array}{l}\text { J Gastroenterol Hepatol (Australia) 27(SUP- } \\
\text { PL.2):58-64 }\end{array}$ & Review \\
\hline Nikhil (2012) & Natl Med J India 25(2):94-95 & Same study (Foster 2011) \\
\hline Nobili (2012) & J Gastroenterol 47(1):29-36 & Review \\
\hline Nseir (2012) & Dig Dis Sci $57(7): 1773-1781$ & Review \\
\hline Nseir (2013) & Curr Atheroscler Rep 15:305 & Review \\
\hline Oben $(2008)$ & CPD Bull Clin Biochem 9(2):47-53 & Review \\
\hline Oni (2013) & J Am Coll Cardiol 61(10):E1427 & Inappropriate primary end point (only laboratory data) \\
\hline Onofrei (2008) & Pharmacotherapy 28(4):522-529 & Review \\
\hline
\end{tabular}




\section{Supplementary Table 3. Continued}

\begin{tabular}{|c|c|c|}
\hline Study & Journal & Reason for exclusion \\
\hline Paragh (2009) & Orv Hetil 150(26):1205-1212 & Review \\
\hline Park (2010) & Clin Chim Acta 411(21-22):1735-1740 & Same study (Park 2011) \\
\hline Park (2011) & J Gastroenterol 46(1):101-107 & Inappropriate study design (single arm study) \\
\hline $\operatorname{Park}(2013)$ & Diabetes Metab J 37(4):240-248 & Review \\
\hline Pastori (2015) & Dig Liver Dis $47(1): 4-11$ & Review \\
\hline Patel (2009) & Gastroenterology 136(5):A847 & Inappropriate primary end point (no steatosis data) \\
\hline Perlemuter (2007) & Nat Clin Pract Endocrinol Metab 3(6):458-469 & Review \\
\hline Pireau (2013) & Acta Clinica Belgica 68(6):463 & Inappropriate primary end point (only laboratory data) \\
\hline Portincasa (2007) & J Gastrointestin Liver Dis 16(2):167-169 & Review \\
\hline Pramfalk (2011) & Curr Opin Lipidol 22(3):225-230 & Review \\
\hline Preiss (2008) & Clin Sci 115(5-6):141-150 & Review \\
\hline Quercioli (2009) & $\begin{array}{l}\text { Cardiovasc Hematol Disord Drug Targets } \\
9(4): 261-270\end{array}$ & Review \\
\hline Rallidis (2004) & Atherosclerosis 174(1):193-196 & Inappropriate study design (single arm study) \\
\hline Ratziu (2007) & Gastroenterol Clin Biol 31(3):333-340 & Review \\
\hline Reihner (1991) & Fortschr Med 109(8):189-194 & $\begin{array}{l}\text { Inappropriate participants (patients with cholecystec- } \\
\text { tomy) }\end{array}$ \\
\hline Renno (2012) & Lab Invest 92:465A-466A & Inappropriate study design (rat model) \\
\hline Riche (2014) & Ann Pharmacother 48(1):137-141 & Inappropriate study design (case study) \\
\hline Riley (2008) & Int J ClinPract 62(3):374-381 & Inappropriate primary end point (only laboratory data) \\
\hline Rizzo (2014) & Expert Opin Pharmacother 15(8):1065-1068 & Review \\
\hline Rizzo (2014) & Curr Vasc Pharmacol 12(5):741-744 & Review \\
\hline Rudovich (2010) & J Hepatol 52(6):952-953 & Inappropriate study design (single arm study) \\
\hline Samy (2011) & $\begin{array}{l}\text { Arab J Gastroenterol 12:80-85 DOI:10.1016/ } \\
\text { j.ajg.2011.04.008 }\end{array}$ & Inappropriate primary end point (only laboratory data) \\
\hline Schattenberg (2011) & Curr Opin Lipidol 22(6):479-488 & Review \\
\hline Schneier (2015) & Expert Rev Gastroenterol Hepatol 9(5):671-683 & Review \\
\hline Schreuder (2008) & World J Gastroenterol 14(16):2474-2486 & Review \\
\hline Schwenger (2014) & World J Gastroenterol 20(7):1712-1723 & Review \\
\hline Seng (2008) & Curr Opin Lipidol 19(6):592-599 & Review \\
\hline Shiwa (2011) & $\begin{array}{l}\text { Nihon Shokakibyo Gakkai Zasshi 108(8):1383- } \\
1392\end{array}$ & Inappropriate study modality (ultrasonography) \\
\hline Siebler (2006) & World J Gastroenterol 12(14):2161-2167 & Review \\
\hline Skrypnyk (2014) & Lik Sprava (5-6):113-121 & Inappropriate participants (patients with heart attack) \\
\hline $\operatorname{Sochman}(2006)$ & Cas Lek Cesk 145(6):443-446; discussion 447-448 & Review \\
\hline Takahashi (2015) & World J Gastroenterol 21(13):3777-3785 & Review \\
\hline Takaki (2014) & Int J Mol Sci 15(5):7352-7379 & Review \\
\hline Takeshita (2011) & J Hepatol 54:S346 & Same study (Takeshita 2014) \\
\hline Takeshita (2011) & Hepatology (Baltimore, MD) 54:1117a & Same study (Takeshita 2014) \\
\hline Tandra (2009) & Curr Treat Options Cardiovasc Med 11(4):272-278 & Review \\
\hline Targher (2010) & Dig Liver Dis 42(5):331-340 & Review \\
\hline Targher (2013) & Semin Thromb Hemost 39(2):214-228 & Review \\
\hline
\end{tabular}




\section{KJIM}

\section{Supplementary Table 3. Continued}

\begin{tabular}{|c|c|c|}
\hline Study & Journal & Reason for exclusion \\
\hline Tilg (2005) & Nat Clin Pract Gastroenterol Hepatol 2(3):148-155 & Review \\
\hline Tolman (2007) & Ther Clin Risk Manag 3(6):1153-1163 & Review \\
\hline Torres (2007) & Curr Treat Options Gastroenterol 10(6):425-434 & Review \\
\hline Torres (2008) & Gastroenterology 134(6):1682-1698 & Review \\
\hline Torres (2012) & Clin Gastroenterol Hepatol 10(8):837-858 & Review \\
\hline Toth (2010) & Clin Lipidol 5(5):655-684 & Review \\
\hline Trovato (2014) & EPMA J 5(1) & Review \\
\hline Tzefos (2011) & J Clin Lipidol 5(6):450-459 & Review \\
\hline Tziomalos (2014) & World J Hepatol 6(10):738-744 & Review \\
\hline Ushio (2012) & Diabetes 61:A458 & Inappropriate study design (rat model) \\
\hline Vuppalanchi (2009) & Hepatology 49(1):306-317 & Review \\
\hline Wierzbicki (2012) & Curr Opin Lipidol 23(4):345-352 & Review \\
\hline Wilkins (2013) & Am Fam Physician 88(1):35-42 & Review \\
\hline Xiao (2013) & Hepatobiliary Pancreat Dis Int 12(2):125-135 & Review \\
\hline Yamagishi (2006) & Med Hypotheses 66(4):844-846 & Review \\
\hline Yamagishi (2013) & Dig Liver Dis $45(1): 82$ & Same study (Hyogo 2012) \\
\hline Yoneda (2010) & Hepatol Res 4O(6):566-573 & Review \\
\hline Yoneda (2011) & Hepatol Res 41(11):1025-1026 & Review \\
\hline Yoneda (2011) & J Gastroenterol 46(3):415-416; author reply 417 & Review \\
\hline Yoshida (2011) & Curr Vasc Pharmacol 9(1):121-123 & Review \\
\hline Younossi (2014) & Aliment Pharmacol Ther 39(1):3-14 & Review \\
\hline $\begin{array}{l}\text { Zvenigorodskaja } \\
(2009)\end{array}$ & Am J Hypertens 22:10 & Inappropriate primary end point (only laboratory data) \\
\hline
\end{tabular}




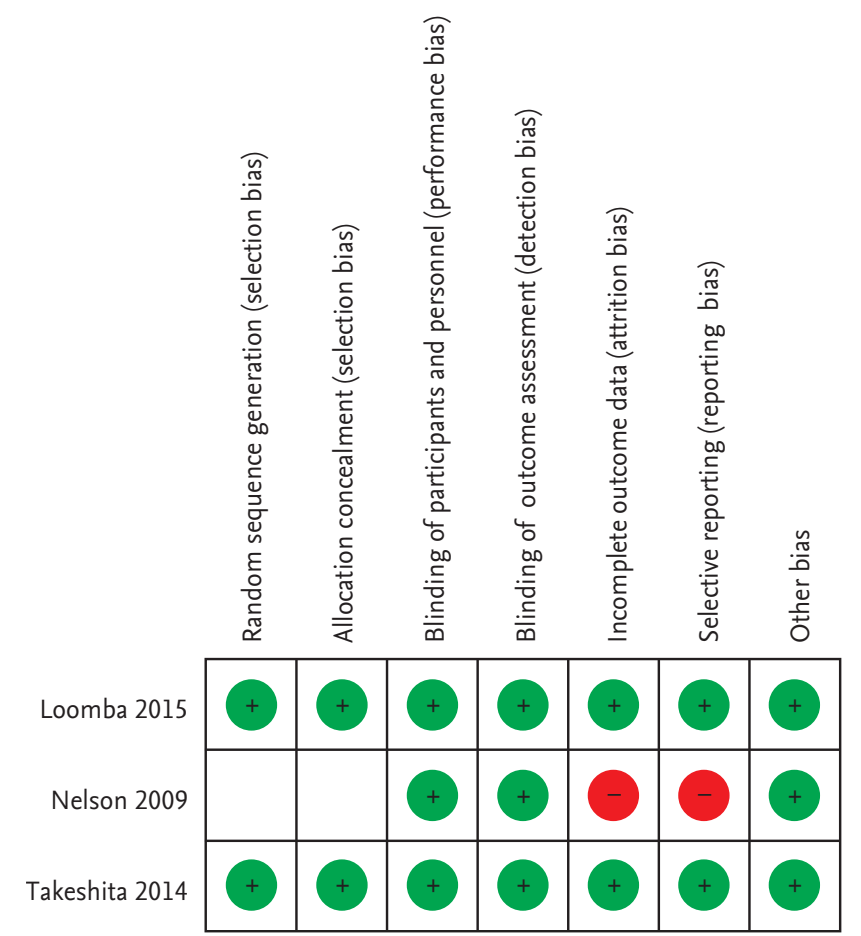

Supplementary Figure 1. Risk of bias summary: review authors' judgments about each risk of bias item for each included study. 


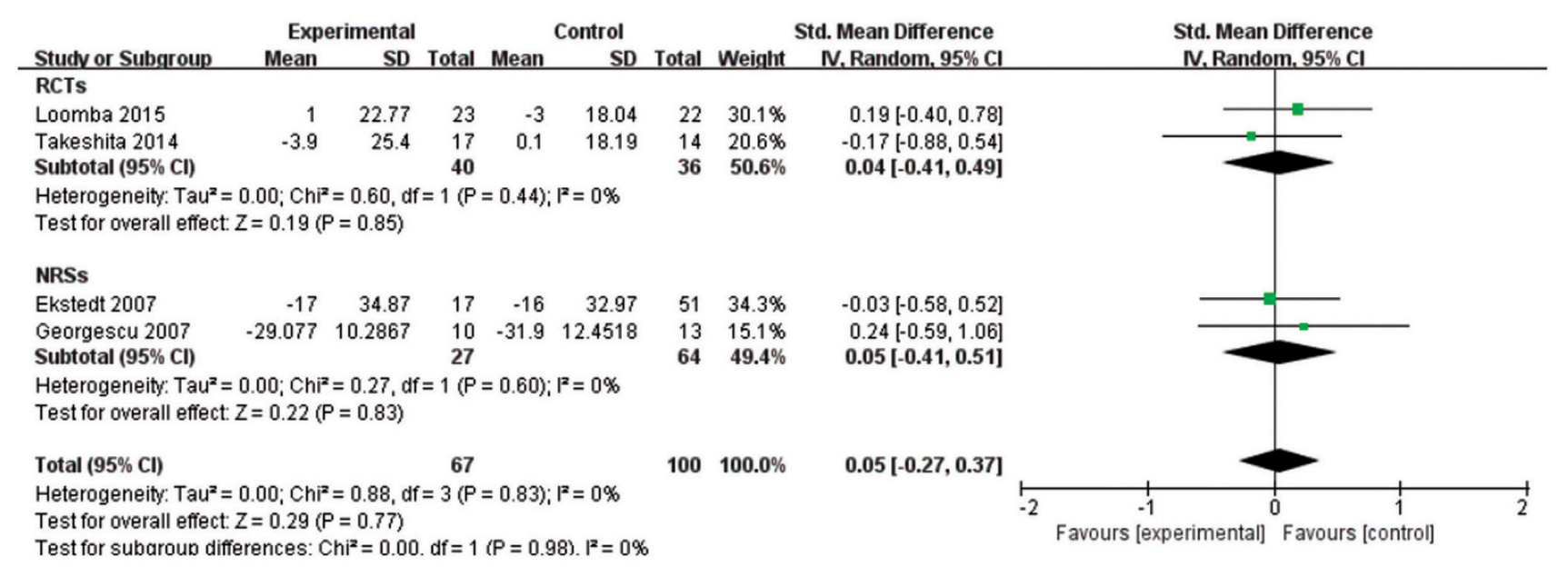

Supplementary Figure 2. Forest plot for decrease of serum alanine aminotransferase (ALT). SD, standard deviation; IV, interval variable; CI, confidence interval; Std., standardized; RCT, randomized controlled trial; NRS, nonrandomized study. 